\title{
Applying Cognitive Therapy for Depression and Anxiety in Mathematics Education for Students' Sustainable Performance
}

\author{
Samuel Adejare Olaoluwa \\ Department of Primary Education, School of Early Childhood Care and Primary Education, Oyo State College of Education, \\ Lanlate, Nigeria \\ Email: jareolaoluwa2017@gmail.com
}

How to cite this paper: Olaoluwa, S. A. (2021). Applying Cognitive Therapy for Depression and Anxiety in Mathematics Education for Students' Sustainable Performance. Creative Education, 12, 1407-1418. https://doi.org/10.4236/ce.2021.126107

Received: April 22, 2021

Accepted: June 27, 2021

Published: June 30, 2021

\section{Copyright (c) 2021 by author(s) and} Scientific Research Publishing Inc. This work is licensed under the Creative Commons Attribution International License (CC BY 4.0).

http://creativecommons.org/licenses/by/4.0/ (c) (i) Open Access

\begin{abstract}
Globally, cases of depression and anxiety have been on the increase among the adolescents. Depression and anxiety interfere significantly on students' academic achievement in schools at all levels. It is more intensed on mathematics learning, reason being that Mathematics as a school subject involves critical thinking, which essentially has to do with the mind-(cognition). It is suffice to say that timely applications of cognitive therapy interventions as preventive measures could ameliorate the incessant of occurrence of depression and mathematics anxiety among students. Therefore, this paper focuses on applying cognitive therapy for depression and anxiety towards enhancing students' sustainable performance in the subject. The paper examines mathematics anxiety, depression, common causes of depression, types of depression, cognitive therapy, basis of cognitive therapy, classroom interventions and treatment techniques, school curriculum configuration repackaging among others. The paper observes that immediate and appropriate classroom interventions would go a long way to restore affected students before it degenerates to complex condition. In this paper, it is noted that chronic depression and mathematics anxiety could significantly impair students' optimal learning. It is therefore recommended that mathematics teachers should be equipped with appropriate classroom interventions, treatment and techniques that could be employed via cognitive therapy to alleviate or minimize the effect of depression and mathematics anxiety among students for sustainable performance.
\end{abstract}

\section{Keywords}

Cognitive Therapy, Mathematics Anxiety and Depression 


\section{Introduction}

Anxiety can be considered the most complicated response to a stressful stimulus. It is an unpleasant excitement that we experience in fear and tension. Anxiety is a warning sign that is aware of an imminent danger and prepares a person for coping. All humans experience anxiety and if it is moderate, it is not only harmful but it is considered as an adapted response, and it makes people always prepare themselves to deal with sudden and threating situations. This kind of anxiety can be considered natural, useful, constructive and at the same time one of the components is of the personality structure (Bazargan \& Amiri, 2018). But on the other hand, there is anxiety that causes failure and obstructions of normal activities (Khodaei, 2015). In general, there are three prominent causes of anxiety, namely: physical factors, social factors and hereditary genetic factors. Mathematics anxiety can be defined as the emotional reaction to fear, tension, helplessness and mental disorganization when dealing with a mathematics problem (Ashcraft, 2002; Fennema \& Sherman, 1976; Zettle, 2003). Anderson, 2007; Hembree, 1990; Lyons \& Beilock, 2010 observed that more generally, this negative emotional reaction or feeling may also be experienced toward mathematics itself. In other words, mathematics anxiety can be considered as a negative feeling toward mathematics or the prospect of doing mathematics. Mathematics anxiety among students has been a global concern as international comparisons of students such as the Trends in International Mathematics and Science Study (TIMSS) indicated that students in many countries experienced mathematics anxiety (Beilock \& Maloney, 2015).

Uusimaki \& Kidman 2004 pointed out that mathematics anxiety can have a substantial physical, psychological and educational impact on students. Students who had mathematics anxiety showed diverse symptoms such as nausea, stomachache and concentration issues. Furthermore, when experienced long-term mathematical anxiety negatively impacted students' mathematics achievement as well as their academic success in College (Erden \& Akgul, 2010; Foss \& Hadfield, 1993; Vitasari, Herawan, Wahab, Othman, \& Sinnadurai, 2010). It is an indisputable fact that learners from broken homes, single parents, orphans, and those who lack parental attention, care and affection are in most cases prone to diverse psychological challenges ranging from uncertainty and hopelessness which are the offsprings of depression and state of being anxious. It is a known fact that once learners are feeling worried about something, learning it becomes harder. "Anxiety really can impact a lot of the things that are important for learning, like attention, memory, and processing speed.", Says Mathew Pagirsky, PsyD, a neuropsychologist at the Child Mind Institute. Feeling anxious also makes people develop self-defeating thoughts like "I'm not good at this" and "I'll never be able to understand this" which increases the stress they are feeling. Mathematics anxiety can also function similarly to test anxiety. The fact that there is a wrong and a right answer in mathematics can be intimidating to young learners who are already a little anxious or afraid of failure. It is obvious that the attendant 
long-term damaging effect of mathematics anxiety is always there; then, it becomes essential, determining what interventions are effective in reducing mathematics anxiety among students for sustainable performance.

Teachers can adopt one of several research-based interventions in their class-rooms that may help lessen their students' mathematical anxiety, thereby increasing students' positive attitudes toward mathematics. These interventions include but are not limited to cooperative and small grouping (Furner \& Duffy, 2002; Lee, Capraro, \& Bicer, 2019), use of manipulative and technology based instruction (Bicer et al., 2018), the identification of problems areas and use of proactive positive approaches (Fotoples, 2000), journal writing and bibliography (Furner \& Duffy, 2002) and orchestrated immersion in brain-based learning strategy (Souse, 2008). These interventions have reduced mathematical anxiety and eventually improved their mathematics achievement (Beilock \& Maloney, 2015; Hembree, 1990; Ramires, Chang, Maloney, Levine, \& Beilock, 2016; Zakaria, Zain, Ahmad, \& Erlina, 2012) one other major challenge among students with mathematics anxiety is depression. Students' challenge in mathematics becomes complex when depression sets in due to some internal factors such as low self-esteem and fear of failure. It becomes more complex when prominent external factors such as mathematics teacher's poor delivery emanating from inadequate methods of teaching, inadequate knowledge of the subject matter, and lack of readiness on the part of the learners. What is depression? Depression is classified as a mood disorder. It may be described as feelings of sadness, loss or anger that interfere with a person's everyday activities. Brody et al. (1999) pointed out that the centers for Disease Control and prevention (CDC) trusted source estimates that 8.1 percent of American adults ages 20 and over had depression in any given 2-week period from 2013 to 2016. As it were in United States of America, so it is in many countries across the globe. People experience depression in different ways. It may interfere with one's daily work, resulting in lost lime and lower productivity. It can also influence relationships and some chronic health conditions. It is important to realize that feeling down times is a normal part of life. Sad and upsetting events happen to everyone. But, if one is feeling down or hopeless on a regular basis, such individual could be dealing with depression. Depression is both a brain disorder and a state of mind.

\section{Symptoms of Depression}

The symptoms of depression can be experienced differently among men, women and children (Brody et al., 1999)

1) Men may experience symptoms related to their Mood: such as anger, aggressiveness, irritability, anxiousness, restlessness; Emotional well-being such as feeling empty, sad, hopelessness; Behaviour: such as loss of interest, no longer finding pleasure in favourite activities, feeling tired easily, thoughts of suicide, drinking excessively, using drugs, engaging in high-risk activities; Sexual interest: such as reduced sexual desire, lack of sexual performance; Cognitive abilities: such as inability to concentrate, difficulty completing tasks, delayed responses 
during conversation; Sleep patterns: such as insomnia, restless sleep, excessive sleepiness, not sleeping through the night; Physical well-being: such as fatigue, pains, headache, digestive problems.

2) Women may experience symptoms related to their. Mood: such as irritability; emotional well-being: such as feeling sad or empty, anxious or hopelessness; behaviour, such as loss of interest in activities, withdrawing from social engagements, thoughts of suicide; cognitive abilities: such as thinking or talking more slowly. Sleep patterns: such as difficulty sleeping through the night, waking early, sleeping too much. Physical well-being: such as decreased energy, greater fatigue, change in appetite, weight changes, aches, pains, headaches, increased cramps.

3) Children may experience symptoms related to their: mood, such as irritability, anger, mood swings, crying; emotional well-being: such as feelings of incompetence (e.g. "I can't do anything right") or despair, crying, intense sadness; behaviuour: such as getting into trouble at school or refusing to go to school; avoiding friends or siblings, thoughts of death or suicide: cognitive abilities: such as difficulty concentrating, decline in school performance, changes in grades, sleep patterns, such as difficulty sleeping or sleeping too much.

Physical well-being, such as loss of energy, digestive problems, changes in appetite, weight loss or gain.

\section{Common Causes of Depression}

There are several possible causes of depression. They can range from biological to circumstantial (Timothy, 2020), few causes identified follows: family history: one is at a higher risk for developing depression if one has a family history of depression or another mood disorder. Early childhood trauma. Some events affect the way our bodies react to fear and stressful situations. Brain structure. there is a greater risk for depression if the frontal lobe of your brain is less active. However, scientists do not know if this happen before or after the onset of depressive symptoms. Medical conditions. Certain conditions may put you at higher risk, such as chronic illness, insomnia, chronic pain, or attention deficit hyperactivity disorder (ADHD). Drug use: A history of drug or alcohol misuse can affect your risk. About 21 percent of people who have a substance use problem also experience depression. In addition, to these causes, other risk factors for depression include: low self-esteem or being self-critical, personal history of mental illness, certain medications, stressful events, such as loss of loved ones, economic problems, or a divorce. It is noted that a vitamin deficiency can trigger symptoms of depression.

\section{Types of Depression}

Depression can be broken into categories depending on the severity of symptoms, some people experience mild and temporary episodes, while others experience sever and ongoing depressive episodes (Brody et al., 1999). There are two main types: major depressive disorder and persistent depressive disorder. Major 
depressive disorder is the more severe form of depression. It is characterized by persistent feelings of sadness, hopelessness, and worthlessness that go away on their own. There are subtypes of major depressive disorder, which the American Psychiatric Association refers to as "specifiers" These include a typical features, anxious distress, mixed features, peripartum onset, during pregnancy or right after giving birth, seasonal patterns, melancholic features, psychotic features and catatonia.

Persistent depressive disorder: persistent depressive disorder (PDD) used to be called or referred to as dysthymia. It is a milder but chronic form of depression. It is common for people with PDD to lose interest in normal daily activities, feel hopeless, lack productivity and has low self-esteem.

\section{Cognitive Therapy}

Is a relatively short-term form of psychotherapy based on the concept that the way we think about things affects how we feel emotionally. Cognitive therapy focuses on present thinking, behaviour and communication rather than on past experiences and is oriented toward problem-solving (Judith \& Beck 2014; Beck. 2014; Greenberger \& Padesku, 1995; Bicer, Perihan, \& Lee, 2020).

Psychologist Aaron Beck developed the cognitive therapy concept in the 1960s. The treatment is based on the principle that maladaptive behaviour (ineffective, self-defeating behaviour) is triggered by inappropriate or irrational thinking patterns, called automatic thoughts, Hope, Burns, Hyes, Herbert, \& Warner (2010). There are six types of automatic thoughts namely: self-evaluated thoughts, thoughts about the evaluation of others, evaluative thoughts about the other person with whom they are interacting, thoughts about coping strategies and behavioural plans, thought of avoidance and any other thoughts that were not categorized. Instead of reacting to the reality of a situation, an individual automatically reacts to his or her own distorted view point of the situation. Brody et al. (1999) pointed out that cognitive therapy focuses on changing these thought patterns (also known as cognitive distortions), by examine in the rationality and validity of the assumptions behind them which is termed cognitive restructuring.

Cognitive therapy is a treatment option for a number of mental disorders including agoraphobia anxiety, or panic disorder, attention deficit-hyperactivity disorder (ADHD), eating disorders, mood disorders, obsessire-compulsive disorders (OCD), personality disorders, post-traumatic disorder, psychotic disorders, schizophrenia, social phobia and substance abuse disorders. It can be useful in helping individuals with anger management problems, and has been reported to be effective in treating insomnia.

\section{Basis of Cognitive Therapy}

Judith \& Beck (2009) pointed out that therapy may consists of testing the assumptions which one makes and looking for new information that could help 
shift the assumption in a way that leads to different emotional or behavioural reactions, change may begin by targeting thoughts (to change emotion and behaviour), behaviour (to change feelings and thought) or the individuals group (by identifying thoughts, feelings or the behaviour that conflict with the goals). Beck et al. (2015) initially focused on depression and developed a list of errors (cognitive distortions) in thinking that he proposed could maintain depression, including arbitrary influence, selective abstraction, over-generalization and magnification (of negative) and minimization (of positive).

As an example of how cognitive therapy might work. Having made a mistake at work, a man may believe, "I'm useless and can't do anything at work" or a mathematics students solving a problem four times and got a wrong answer in each of the four consecutive times.

The man may then focus on the mistake (which he takes as evidence that his belief is true) and his thoughts about being "useless" are likely to lead to negative emotion (frustration, sadness, hopelessness). Given these thoughts and feelings, he may then begin to avoid challenges at work, which is behaviours that could provide even more evidence for him that his belief is true. As a result, any adaptive response and further constructive consequences become unlikely and he may focus even more on any mistakes he may make, which serve to reinforce the original belief of being "useless". In therapy, this example should be identified as a self-fulfilling prophecy or "problem-cycle" and the efforts of the therapists, and patient would be directed at working together to explore and shift this cycle.

People who are working with a cognitive therapist often practice the use of more flexible ways to think and respond, learning to ask themselves whether their thoughts are completely true and whether these thoughts are helping them to meet their goals. Thoughts that do not meet this description may then be shifted to something more accurate or helpful, leading to more positive emotion, more desirable behaviour and movement towards the person's goals. Judith and Beck (2014) opined that Cognitive therapy takes a skill-building approach, where the thought help the person to learn and practice these skills independently, or eventually, "becoming his" or her own therapist.

\section{Treatment Techniques}

Cognitive therapy is usually administered in an out-patient setting clinic or doctor's office by a therapist trained or certified in cognitive therapy techniques. Therapists use several techniques in the course of cognitive therapy to help patients examine thoughts and behaviours. Beck, Davis, \& Freeman (2015); Beck \& Bredemeirer (2016).

These include:

1) Validity testing: This therapist asks the patient to defend his or her thoughts and beliefs. If the patient cannot produce objective evidence supporting his or her assumptions the invalidity or faulty nature is expected.

2) Cognitive rehearsal: The patient is asked to imagine a difficult situation he 
or she has encountered in the past, and then works with the therapist to practice how to successfully cope with the problem. When the patient is confronted with a similar situation again, the rehearsed behaviour will be drawn on to deal with it.

3) Guided discovery: The therapist ask the patient a series of questions designed to guide the patient towards the discovery of his or her cognitive distortions.

4) Journaling: Patients keep a detailed written dairy of situations that arise in everyday life, the thoughts and emotions surrounding them, and the behaviour that accompany them. The therapist and patient then review the journal together to discover maladaptive thoughts patterns and how these thoughts impact behaviour.

5) Homework: in order to encourage self-discovery and reinforce insights made in therapy, the therapist may ask the patient to do homework assignments. These may include note taking during the session, journaling, review of an audiotape of the patient session, or reading books or articles appropriate to the therapy. They may also be more behaviorally focused, applying a newly learned strategy or coping mechanism to a situation, and then recording the results for the next therapy session.

6) Modelling: Role-playing exercises allow the therapist to act out appropriate reactions to different situations. The patient can then model this behaviour.

7) "Neurons that fire together wired" allow learners to teach the topic or concept they are being taught in rotational basis. This approach will enable them to develop self-confidence in the long run.

\section{A Need for School Curriculum Configuration Repackaging}

The present school curriculum configuration is highly concentrated on cognition at the expense of the other two domains of learning viz: affective and psychomotor. It is not a far-fetched fact that too much stress on cognition could lead to depression and anxiety particularly when a learner has to think, reason and fashion out solutions to diverse tasks within a time frame. The present school curriculum should be repackaged to accommodate the three domains of learning: cognitive, psychomotor and affective $(55 \%, 30 \% \& 15 \%$ or ration 11:6:3) respectively. Inclusion of greater workload on practical makes the learners lively and relaxed and at the same time reduces unnecessary tension and fear of failure.

\section{A Need for Shift of Paradigm from Lump Sum Awards of Marks to Sectional Awards of Marks}

Awarding long marks can be discouraging and demoralizing especially when the answer is wrong e.g. solve the following quadratice equation

$$
x^{2}-6 x+9=0
$$

\section{Student A}


Solution

$$
\begin{gathered}
x^{2}-6 x+9=0 \\
x^{2}-3 x-3 x+9=0 \\
\left(x^{2}-3 x\right)(-3 x+9)=0 \\
x(x-3)-3(x-3)=0 \\
(x-3)(x-3)=0 \\
(x-3)=0 \text { or }(x-3)=0 \\
x-3=0 \text { or } x-3=0 \\
\therefore x=3 \text { or } x=3 \\
\text { hence } x=3 \text { twice }
\end{gathered}
$$

\section{Student B}

Solution

$$
\begin{gathered}
x^{2}-6 x+9=0 \\
x^{2}-3 x+3 x+9=0 \\
\left(x^{2}-3 x\right)(+3 x+9)=0 \\
x(x-3)+3(x+3)=0 \\
(x-3)(x+3)=0 \\
(x-3)=0 \text { or }(x+3)=0 \\
x-3=0 \text { or } x+3=0 \\
\therefore x=3 \text { or } x=3 \\
\text { hence } x=3 \text { or } x=-3
\end{gathered}
$$

Student C

Solution

$$
\begin{gathered}
x^{2}-6 x+9=0 \\
x^{2}-3 x+3 x+9=0 \\
\left(x^{2}-3 x\right)(-3 x+9)=0 \\
3\left(x^{2}-1\right)+3(1 x+3)=0 \\
\frac{3\left(x^{2}-1\right)}{3}+\frac{3(1 x+3)}{3}=0 \\
\left(x^{2}-1\right)(1 x+3)=0 \\
\left(x^{2}+1\right)=0(x+3)=0 \\
x^{2}=1 \text { or } x=3
\end{gathered}
$$

There is need for paradigm shift in awarding marks, lump sum marks is de- 
ceptive, discouraging and dehumanizing. For instance, in the above illustration, adopting lump sum marks, student $A$ will be awarded full marks while student $B$ and student $\mathrm{C}$ will be awarded wrong marks despite the fact that they got some line or points right. It will be appropriate to award marks on methods and accuracy as obtainable in standardized examinations. By implication student $\mathrm{A}$ would get full marks on method and accuracy, assuming method is 4 marks and accuracy 1 mark. Student B would loose accuracy mark and got 2 1/2 marks while student $C$ would be awarded 1 1/2 marks for method and loose accuracy marks. When this is done, students B and C would now sit themselves down and compare their work with student A occurred to see by themselves where the errors are committee.

This implies that Students B and C are tactfully encouraged and motivated to be more meticulous in subsequent exercises for better performance.

\section{Conclusion}

Mathematics educators have observed that the art of learning mathematics involves critical thinking. It is a thing of the mind. It is evident that interference would definitely affect assimilation of concepts in mathematics classroom.

- The menace of depression has crept in due to a lot of factors and it has affected a lot of young people.

- It therefore becomes obvious that teachers of mathematics have a lot of job to do in the process of teaching mathematics, particularly to this generation.

- It has been said that man's mind is a battle ground-with a lot of unspecified conversations, thoughts going on even as the lesson progresses.

- Utilizing the classroom cognitive therapy interventions, treatment and techniques of alleviating depression and mathematics anxiety demands that mathematics teachers be adequately equipped.

- School curriculum configuration repackaging is inevitable to lessen much workload placed on cognitive domain.

\section{Recommendations}

- Cognitive therapy unit should be set up in every school apart from counseling unit, to cater for students with any form of depression whether major or persistent type.

- Observational technique should be adopted in schools for on the spot assessment of students' with depressive symptoms.

- Workshops/seminars should be organized for teachers on cognitive therapy approach.

- School environment needs highly attractive with designated spots for relaxation and well-equipped mathematics spots and indoors mathematical games in a functional mathematics laboratory.

- Teachers should maintain a friendly atmosphere all through the school day in such a way that as students are closing for the day work, they are eager to 
return the following school day, making even the weekend to be boring for them at home; ultimately school life then becomes the best.

- Students from broken homes, orphans and less privileged families, need teacher's special attention in terms of care, support and encouragement on a regular basis.

- Most of the school curriculums place much workload on cognition at the expense of the other two domains (affective and psychomotor) which in some cases leads to stress and sometimes translates to depression.

- It is therefore expedient to restructure and apportion learning episode to other two domains in the school curriculum as much as practicable.

- Teachers need to maintain a form of relaxed, alertness in the classrooms i.e. complete avoidance of threat and fear while maintaining a highly challenging environment.

- "Neurons that fire together wired together" allow learners to teach the topic or concept they are being taught in rotational basis. This would enable them to develop self-confidence while destroying low self-esteem on a gradual basis.

- It is observed that the present school curriculum configuration is extremely cognition-based. There is a need for restructuring that will put the other two domains: affective and psychomotor at optimal use.

\section{Conflicts of Interest}

The author declares no conflicts of interest regarding the publication of this paper.

\section{References}

Anderson, V. (2007). An Online Survey to Assess Student Anxiety and Attitude Response to Six Different Mathematical Problems. In J. Watson, \& K. Bcswiek (Eds.), Proceeding of the 30th Annual Conference of the Mathematics Education Research Group of Australasia (pp. 93-102). Adelaide: Merga.

Ashcraft, M. H. (2002). Math Anxiety: Personal, Educational, and Cognitive Consequences. Current Directions in Psychological Science, 11, 181-185.

https://doi.org/10.1111/1467-8721.00196

Bazargan, M., \& Amiri, M. (2018). The Effectiveness of Modular Cognitive Behavioural Therapy on Mathematical Anxiety and Assertiveness in Students. Mashhad: Psychiatry and Behavioural Sciences Research Center, Ibn-Sina Hospital. http://jfmh.mums.ac.ir

Beck, A. T. (2014). Advances in Cognitive Therapy and Therapy Review in Clinical Psychology.

Beck, A. T., \& Bredemier, K. (2016). A Unified Model of Depression: Integrating Clinical Cognitive, Biological, and Evolutionary Perspectives. Clinical Psychological Science, 4, 596-619. https://doi.org/10.1177/2167702616628523

Beck, A. T., Davis, D. D., \& Freeman, A. (2015). Cognitive Therapy of Personality Disorders. Now York: Guilford Publications.

Beilock, S. L., \& Maloney, E. A. (2015). Math Anxiety: A Factor in Math Achievement Not to Be Ignored. Policy Insights from the Behavioral and Brain Sciences, 2, 4-12. 
https://doi.org/10.1177/2372732215601438

Bicer, A., Lee, Y., C’apraro, R. M., Capraro, M. M., Rarroso, L. R., Bevan, D., \& Vela, K. (2018). Cracking the Code: The Effects of Using Microcontrollers to Code on Students' Interest in Computer and Electrical Engineering. 2018 IEEE Frontiers in Education Conference, San Jose, 3-6 October 2018, 1-7. https://doi.org/10.1109/FIE.2018.8658617

Bicer, A., Perihan, C., \& Lee, Y. J. (2020). A Meta-Analysis: The Effects of CBT as a Clinic- \& School-Based Treatment on Students' Mathematics Anxiety. International Electronic Journal of Mathematics Education, 15, em0576. https://doi.org/10.29333/iejme/7598

Brody, A. L., Saxena, S., Silverman, D. H. S., Alborazian, S., Fairbanks, L. A., Phelps, M. E. et al. (1999). Brain Metabolic Changes in Major Depressive Disorder from Pre-to-Post Treatment with Paroxetine. Psychiatry Research: Neuroimaging, 91, 127-133. https://doi.org/10.1016/S0925-4927(99)00034-7

Clark, D. A., \& Beck, A. T. (2011). Cognitive Therapy of Anxiety Disorders: Science and Practice. New York: The Guilford Press.

Erden, M., \& Akgul, S. (2010). Predictive Power of Mathematics Anxiety and Perceived Social Support from Teacher for Primary Students' Mathematics Achievement. Journal of Theory and Practice in Education, 6, 3-16.

Fennema, E., \& Sherman, A. (1976). Fennema \& Sherman Mathematics Attitudes Scales: Instruments Designed to Measure Attitudes toward the Learning of Mathematics by Females and Males. Journal for Research in Mathematics Education, 7, 321-326. https://doi.org/10.2307/748467

Foss, D. H., \& Hadfield, O. D. (1993). A Successful Clinic for the Reduction of Mathematics Anxiety among College Students. College Student Journal, 27, 157-165.

Fotoples, R. M. (2000). In My View: Overcoming Math Anxiety. Kappa Delta pi Record, 36, 149-151. https://doi.org/10.1080/00228958.2000.10518774

Furner, J. M., \& Duffy, N. L. (2002). Equity for All Students in the New Millennium Disabling Math Anxiety. Intervention in School and Clinic, 38, 67-74.

Greenberger, D., \& Padesku, C. (1995). Mind over Mood: A Cognitive Therapy Treatment Manual for Clients. New York: Guilford Press.

Hembree, R. (1990). The Nature, Effects, and Relief of Mathematics Anxiety. Journal for Research in Mathematics Education, 21, 33-46. https://doi.org/10.5951/jresematheduc.21.1.0033

Hope, D. A., Burns, J. A., Hayes, S. A., Herbert, J. D., \& Warner, M. D. (2010). Automatic Thoughts and Cognitive Restructuring in Cognitive Behaviour Group Therapy for Social Anxiety Disorder. Cognitive Therapy Research, 34, 1-12. https://doi.org/10.1007/s10608-007-9147-9

Judith, S., \& Beck, A. T. (2009). Cognitive Therapy. Basics and Beyond. North America Journal of Psychology, 11, No. 1.

Judith, S., \& Beck, A. T. (2014). Questions and Answers about Cognitive Therapy. https://www.gatewaypsychiatric.com

Khodaei, S. (2015). Mathematical Anxiety in Students (3rd ed.). Isfahan: Khoein. (Persian)

Lee, Y., Capraro, R. M., \& Bicer, A. (2019). Affective Mathematics Engagement: A Comparison of STEM PBL versus Non-Stem PBL Instruction. Canadian Journal of Science, Mathematics, and Technology Education, 19, 270-289.

https://doi.org/10.1007/s42330-019-00050-0

Lyons, I. M., \& Beilock, S. L. (2010). Mathematics Anxiety: Separating the Math from the 
Anxiety. The Annual Psychonomic Meeting, St. Louis, 20 October 2011, 2100-2108.

Ramires, G., Chang, H., Maloney, E. A., Levine, S. C., \& Beilock, S. L. (2016). On the Relationship between Math Anxiety and Math Achievement in Early Elementary School: The Role of Problem Solving Strategies. Journal of Experimental Child Physiology, 141, 83-100. https://doi.org/10.1016/j.jecp.2015.07.014

Souse, D. A. (2008). How the Brain Learns Mathematics. Thousand Oaks, CA: Corwin Press.

Timothy, J. L. (2020). Everything You Want to Know about Depression. Medical Review Written by Valencia Higuera-Updated on February 11, 2020.

Uusimaki, L. S., \& Kidman, G. C. (2004). Challenging Math Anxiety: An Intervention Model. The 10th International Congress on Mathematical Education (ICME-10), Copenhagen, 4-11 July 2004. https://doi.org/10.11120/msor.2004.04030064

Vitasari, P., Herawan, T., Wahab, M. N. A., Othman, A., \& Sinnadurai, S. K. (2010). Exploring Mathematics Anxiety among Engineering Students. Procedia-Social and Behavioural Science, 8, 482-489. https://doi.org/10.1016/j.sbspro.2010.12.066

Zakaria, E., Zain, N. M., Ahmad, N. A., \& Erlina (2012). Mathematics Anxiety and Achievement among Secondary School Students. American Journal of Applied Science, 9, 1828-1832. https://doi.org/10.3844/ajassp.2012.1828.1832

Zettle, R. D. (2003). Acceptance and Commitment Therapy (ACT) vs. Systematic Desensitization in Treatment of Mathematics Anxiety. The Psychological Record, 53, 197-215. https://doi.org/10.1007/BF03395440 